\title{
PROFITABILTAS MEMODERASI LIKUIDITAS DAN GROWTH OPPORTUNITY TERHADAP NILAI PERUSAHAAN
}

\author{
Ati Retnasari' ${ }^{1}$, Supami Wahyu Setiyowati ${ }^{2}$, Mochamad Fariz Irianto ${ }^{3}$ \\ Universitas Kanjuruhan Malang 1,2,3, \\ Jl. S. Supriyadi No. 48 Malang Jawa Timur, 65148, Indonesia \\ e-mail: mochamadfarizirianto@unikama.ac.id ${ }^{3}$
}

\section{Abstract}

This study aims to determine whether provitability is able to moderate the relationship of liquidity and growth to the value of the company. The value of the company is a value that reflects the credibility of the company in the eyes of the public, especially investors and prospective investors. The sample of this research is 58. This study uses multiple analyst regressions in the data analyst. The results showed that liquidity and growth had a negative effect on firm value. Profitability moderates the relationship of liquidity and growth to the value of the company.

Keywords: Liquidity, growth opportunity, profitability, company value

\section{Abstrak}

Penelitian ini bertujuan untuk mengetahui apakah profitabilitas mampu memoderasi hubungan likuiditas dan pertumbuhan terhadap nilai perusahaan Nilai perusahan merupakan nilai yang mencerminkan kredibilitas perusahaan dimata masyarakat khususnya investor dan calon investor.Populasi penelitian digunakannya perusahaan manufaktur yang terdaftar di BEI periode 2015-2016. Sampel penelitian berjumlah 58. Penelitian ini menggunakan multipel regresi analis dalam analis data. Hasil penelitian menunjukan bahwa likuiditas dan pertumbuhan berpengaruh negatif terhadap nilai perusahaan. Profitabilitas memoderasi hubungan likuiditas dan pertumbuhan terhadap nilai perusahaan.

Kata kunci: Likuiditas,growth opportunity, profitabilitas,nilai perusahaan

\section{PENDAHULUAN}

Persaingan yang semakin hebat di era globalisasi ini, menerapkan improvement terhadap nilai perusahaan merupakan tujuan jangka panjang perusahaan yang akan tercermin dari harga pasar sahamnya karena evalusi dari investor terhadap perusahaan dapat diamati melalui pergerakan harga saham perusahaan yang ditransaksikan di bursa buat industri yang telah go public.

Nilai perusahaan ialah situasi khusus yang sudah tercapai pada perusahaan tersebut. Dimana kondisi tersebut menunjukkan kepercayaan masyarakat kepada perusahaan dilalui proses beberapa tahun, terhitung sejak emiten didirikan sampai saat ini. Prestasi yang dicapai perusahaan dapat berupa peningkatan nilai perusahaan. Peningkatann nilai perusahaan apabila manajemen dapat terjalin hubungan kerja sama dengan baik dalam pembuatan 
Ati Retnasari, Supami Wahyu Setiyowati, Mochamad Fariz Irianto : Profitabiltas Memoderasi Likuiditas Dan Growth Opportunity Terhadap Nilai Perusahaan

keputusan-keputusan keuangan contohnya mengelola aset dan laba yang dilaksanakan manajemen bersumber pada laporan keuangan.

Likuiditas yaitu mampunya perusahaan ketika pelunaasan current liabilities. Kemampuan perusahaan ini akan mempengaruhi nilai perusahaan.Likuiditas diukur menggunaka perbandingan hutang lancar dengan aset lancar. Hasil ini menunjukkan semakin tinggi perusahaan mempunyai kemampuan yang baik untuk pembayaran current liabilities (Kasmir, 2018).

Pertumbuhan perusahaan menjadi indikator yang sangat signifikan bagi investor. Investor akan sangat tertarik dalam menginvestasikan modal di perusahaan jika perusahaan itu mengalami pertumbuhan. Pertumbuhan perusahaan adalah mampunya perusahaan dalam peningkatan ukuran perusahaan melalui peningkatan aset Pertumbuhan perusahaan dapat diukur dengan menggunakan pertumbuhan aset dan pertumbuhan penjualan (Kasmir, 2018).

Profitabilitas yakni mampunya emiten dalam mendapatkan laba dari aktivitas perusahaan. Kemampuan manajemen perusahaan terlihat dari profitabilitas yang di peroleh pada satu periode. profit yang tinggi dapat memiliki dampak peningkatan pada nilai perusahaan. Rasio profitabilitas yang akan dipakai pada penelitian ini Return On Aset (ROA). ROA ialah mampunya emiten dalam mendapatkan laba dengan tergunakannya aset emiten (Tandelilin, 2010).

Penelitian tentang pengaruh likuiditas dan pertumbuhan telah dilakukan tetapi hasilnya berbeda beda. Hasil penelitian menjelaskan profitabilitas dan pertumbuhan memengaruhi positif pada nilai perusahaan(Fajaria \& Isnalita, 2018). Sedangkan laverage dan likuiditas memengaruhi negatif pada nilai perusahaan. Penelitian (Tahu \& Susilo, 2017) likuiditas dan laverage tidak memiliki pengaruh terhadap nilai perusahaan. Sedangkan profitabilitas memengaruhi positif terhadap nilai perusahaan. (Jacob \& Taslim, 2017) menunjukkan likuiditas dan profitabilitas memengaruhi nilai perusahaan.

Penelitian yang tidak sejalan terjadi maka peneliti tertarik meneliti kembali pengaruh likuiditas dan growth opportunity terhadap nilai perusahan di moderasi profitabilitas.

Objek penelitian ini ialah perusahaan manufaktur. Perusahaan manufaktur ialah emiten yang mengubah bahan baku menjadi barang jadi dan menjualnya kepada konsumen. Masalah penelitian ini adalah apakah likuiditas dan growth opportunity memengaruhi nilai perusahaan di moderasi profitabilitas.

\section{KAJIAN PUSTAKA}

\section{Nilai Perusahaan}

Nilai perusahaan ialah presepsi pemodal pada keseluruhan modal yang dimiliki emiten dengan keterkaitan pada harga saham. Harga saham bersumber pada harga saham penutupan. Kepercayaan masyarakat yang tinggi di peroleh 
Ati Retnasari, Supami Wahyu Setiyowati, Mochamad Fariz Irianto : Profitabiltas Memoderasi Likuiditas Dan Growth Opportunity Terhadap Nilai Perusahaan

ketika harga saham tinggi. Hal ini disebabkan pemodal percaya bahwa harga saham yang tinggi menunjukan tingakat pengembalian yang akan diterima juga tinggi. Perusahaan yang mempunyai harga saham yang tinggi dapat terjadi peningkatan taraf hidup pemiliknya

(H. K. Sari \& Priyadi, 2016) Nilai perusahaan pada penelitian diukur melalui Rumus Tobin's Q dengan rumus:

$$
Q=\frac{(E M V+D)}{(E B V+D)} \times 100 \%
$$

Dimana :

$\mathrm{Q} \quad=$ Nilai perusahaan

EMV = Nilai pasar ekuitas $(E M V=$ closing price $\mathrm{x}$ jumlah saham yang beredar $)$

$\mathrm{EBV}=$ Nilai buku dari total aset $(\mathrm{EBV}=$ total aset-total utang)

$\mathrm{D} \quad=$ Nilai buku dari total hutang

\section{Likuiditas}

Likuiditas merupakan rasio untuk pengukuran mampunya perusahaan untuk terpenuhinya hutang yang jatuh tempo, baik hutang pada pihak eksternal perusahaan atau kewajiban eksternal perusahaan. Likuiditas adalah kemampuan perusahaan untuk membayar kewajiban jangka pendek. Rasio yang digunakan dalam pengukuran likuiditas adalah rasio lancar. Rasio lancar adalah rasio untuk pengukuran mampunya perusahaan dalam membayarkan hutang jangka pendek dan utang yang segera jatuh tempo pada saat ditagih secara keseluruhan. Semakin bagus nilai risk likuiditas maka semakin bagus kesehatan perusahaan menurut bank. Rumus rasio lancar (current ratio) menurut (Kasmir, 2018) yaitu Current Ratio $=\frac{\text { current aset }(\text { aset lancar })}{\text { current liabilities }(\text { utang lancar })} \times 100 \%$

\section{Growth opportunity}

Growth opportunity atau pertumbuhan perusahaan ialah faktor yang diharapkan pemilik ataupun pemodal terhadap perusahaan. Terlihat pada sisi pemodal,perusahaan yang mengalami pertubuhan terus menerus memiliki peluang atau prospek masa depan yang baik. Perusahan yang memiliki pertumbuhan akan memberikan return yang tinggi sesuai dengan pertumbuhannya(Suastini, Purbawangsa, \& Rahyuda, 2016). Growth opportunity dalam penelitian ini di uku menggunakan rumus :

$$
\text { Total } \text { Asset }_{t} \text { - Total Asset }{ }_{t-1}{ }^{\prime}
$$

Pertumbuhan Aset=

$$
\text { Total Asset } \mathrm{t}-1
$$

Keterangan :

TAt $=$ Total aset tertentu

TA $\mathrm{t}-1=$ Total aset tahun sebelumnya 
Ati Retnasari, Supami Wahyu Setiyowati, Mochamad Fariz Irianto : Profitabiltas Memoderasi Likuiditas Dan Growth Opportunity Terhadap Nilai Perusahaan

\section{Profitabilitas}

Profitabilitas dalam penelitianini menggunakan ROA. ROA ialah penggambaran (return) atas total aset yang digunakan dalam perusahaan. Selain itu, profitabilitas perusahaan yang diukur dengan ROA didapatkan ukuran yang sangat baik dikarenakan keefektivitas manajemen dalam penggunaan aktiva dalam memperolehnya pendapatan Kasmir (Kasmir, 2018) . Rumus yang digunakan ialah Return on Aset menurut (Kasmir, 2018) dapat dirumuskan sebagai berikut:

Return on aset $=\frac{\text { Laba bersih }}{\text { Total } \text { aset }} \times 100 \%$

\section{Kerangka koseptual}

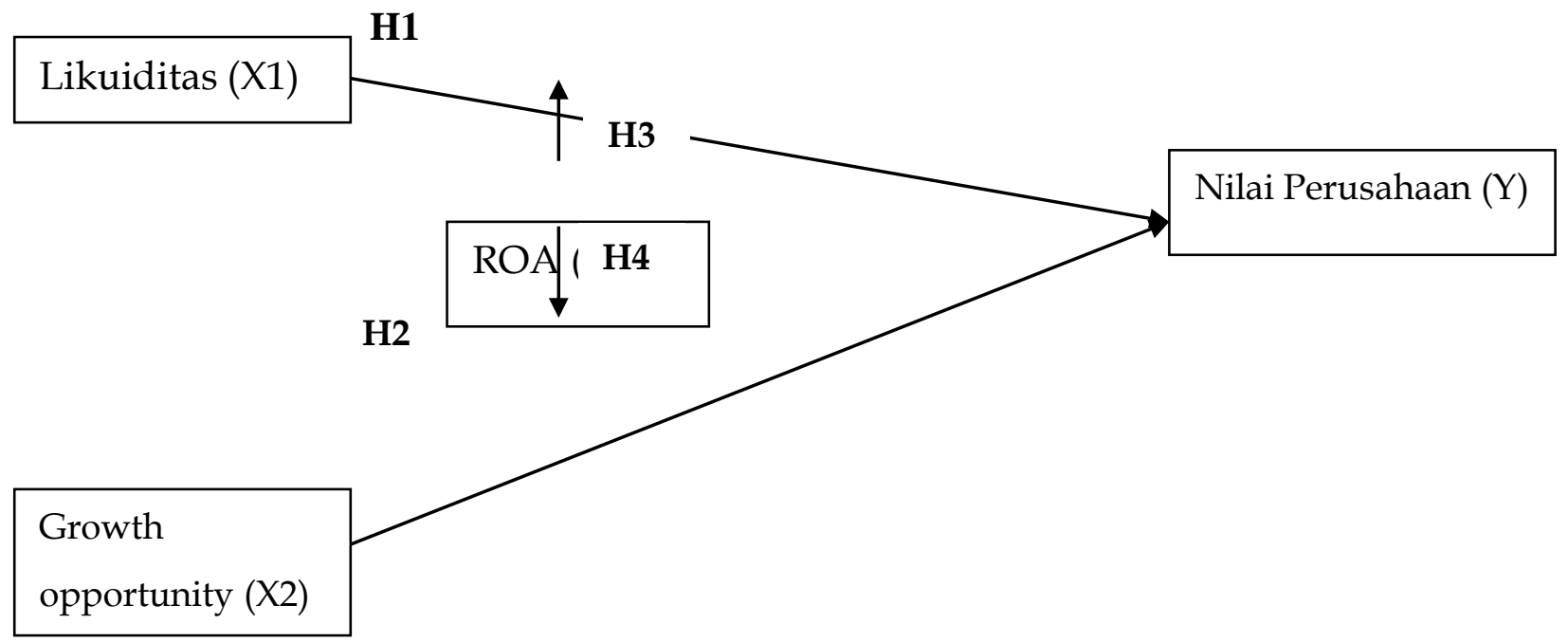

\section{Gambar 1. Kerangka Konseptual Sumber: Diolah Peneliti (2020)}

\section{HIPOTESIS}

Mampunya perusahaan dalam pembayaran current liabilities adalah likuiditas. Makin tinggi rasio likuiditas makin tinggi kepercayaan bank maupun investor terhadap perusahaan. Bank akan memberi kepecayaan dalam hal pendanaan. Investor memiliki sinyal yang baik dalam penanaman modal pada emiten. Sesuai Penelitian (Rompas, 2013) dan (Lestari \& Hermanto, 2015) menunjukan bahwa likuiditas memengaruhi nilai perusahan. Likuiditas merupakan rasio dan digunakan pengukuran kemampuan emiten serta terpenuhi hutang yang jatuh tempo, baik hutang pada pihak eksternal emiten (likuiditas badan usaha) atau hutang internal (likuiditas perusahaan)(Kasmir, 2018). Perusahaan dengan likuiditas yang baik maka mempunyai memiliki resiko rendah, penyebabnya emiten memnuhi kewajiban dengan baik, banyak dana yang dimiliki perusahaan untuk melakukan pembayaran dividen, membayar 
Ati Retnasari, Supami Wahyu Setiyowati, Mochamad Fariz Irianto : Profitabiltas Memoderasi Likuiditas Dan Growth Opportunity Terhadap Nilai Perusahaan

operasi dan investasi. Perusahaan yang mampu mengelola hutang jangka pendek akan mampu meningkatkan nilai perusahaan.

\section{H1: Likuiditas berpengaruh terhadap nilai Perusahaan}

Growth opportunity merupakan kondisi perusahaan memiliki aspek yang menguntungkan, dan investor pun akan mengharapkan tingkat pengembalian. Suatu emiten dengan growth yang baik akan memberi sinyal bagi calon investor dan investor untuk menanam modalnya bagi perusahaan. Hal ini terjadi peningkatan nilai perusahaan. Penelitian hubungan growth opportunity dengan nilai perusahaan di lakukan (Oh \& Kim, 2016) dan (Abdullah, Ali, \& Haron, 2017). Penelitian ditunjukkan pertumbuhan perusahaan mempunyai pengaruh dengan nilai perusahaan.

\section{H2: Growth opportunity berpengaruh terhadap nilai perusahaan}

Perusahaan yang mampu memaksimalkan penggunaan aset dalam aktivitas perusahaan akan mendapatkan laba yang maksimal. Laba yang maksimal akan mengurangi hutang jangka pendek. Hutang jangka pendek akan dapat dibayar tepat waktu. Dengan ini akan memiliki dampak nilai perusahaan. Kemampuan manajemen untuk meingkatkan nilai perusahaan merupakan sinyal positif bagi investor dan calon investor. (Fajaria \& Isnalita, 2018) membuktikan laba mempengaruhi nilai perusahaan. (Jacob \& Taslim, 2017) juga membuktikan kemampuan perusahaan membayar utang dan laba berpengaruh terhadap nilai perusahaan..

H3: keterkaitan likuiditas terhadap nilai perusahaan di moderasi profitabilitas

Laba dihasilkan emiten sebagian digunakan untuk pembayaran utang yang sudah jatuh tempo. Kemampuan perusahan untuk membayar hutang yang jatuh tempo merupakan salah satu prestasi perusahaan. Hasil penelitian (P. I. P. Sari \& Abundanti, 2014) yang menyatakan pertumbuhan memengaruhi profitabilitas. Profitabilitas merupakan laba yang dihasilkan deri penggunaan aset yang dimiliki perusahaan.. Pertumbuhan perusahaan yang semakin cepat menunjukkan semakin tinggi kemampuan perusahaan dalam menghasilkan keuntungan. Penelitian (Lestari \& Hermanto, 2015) ditunjukkan pertumbuhan perusahaan memengaruhi profitabilitas. Growth perusahaan yang meningkat dapat memiliki dampak pada peningkatan profitabilitas dan nilai perusahaan.

H4: Profitabilitas memoderasi hubungan growth opportunity terhadap nilai perusahaan.

\section{METODE}

Penelitian ini adalah kuantitatif. Tempat penelitian pada Galeri Investasi Bursa Efek Indonesia dii Universitas Kanjuruhan. Penelitian ini yakni penelitian basis pengujian hipotesis. Pengujian pada penelitian ini dilakukan berdasarkan data sekunder

Populasi penelitian ialah perusahan manufaktur yang ada pada BEI tahun 2015 - 2016. Jumlah sampe penelitian 58 perusahaan dipilih dengan simple 
Ati Retnasari, Supami Wahyu Setiyowati, Mochamad Fariz Irianto : Profitabiltas Memoderasi Likuiditas Dan Growth Opportunity Terhadap Nilai Perusahaan

random sampling.. Data dianalis menggunakan multipel regresi analis (MRA). Persamaanya sebagi berikut:

$$
\mathrm{Q}=\beta 0+\beta 1 \mathrm{CR}+\beta 2 \mathrm{GO}+\beta 3 \mathrm{CR} * \mathrm{ROA}+\beta 4 \mathrm{GO} * \mathrm{ROA}+\mathrm{e}
$$

Keterangan: $Q$ merupakan nilai perusahaan.CR untuk menghitung likiditas,GO digunakan untuk menghitung pertumbuhan. ROA di gunakan untuk menghitung provitabilitas

\section{Hasil Uji Asumsi Klasik}

Hasil normalitas digunakannya Kolmogorof-Smirnov, nilai. sig (2-tailed) 0,053 > 0,05 (alpa 5\%). Data penelitian dinyatakan normal. Uji multikolinieritas dengan VIF (Variance Inflation Factor), nilai VIF variabel likuiditas (CR) $=3.298$ ,growh opportunity $(\mathrm{GO})=3.046$ profitabilitas $(\mathrm{ROA})=5,709, \mathrm{CRROA}=8,428$ dan GOROA $=3,892$ menunjukkan $<10$. Maka disimpulkan tidak terjadi multikolinieritas Pengujian heteroskedastisitas dengan scatterplot, memberikan hasil scatterplot tidak beraturan dengan kata lain tidak terbentuk pola maupun gambar tertentu, jadi tidak terjadi heteroskedastisitas.

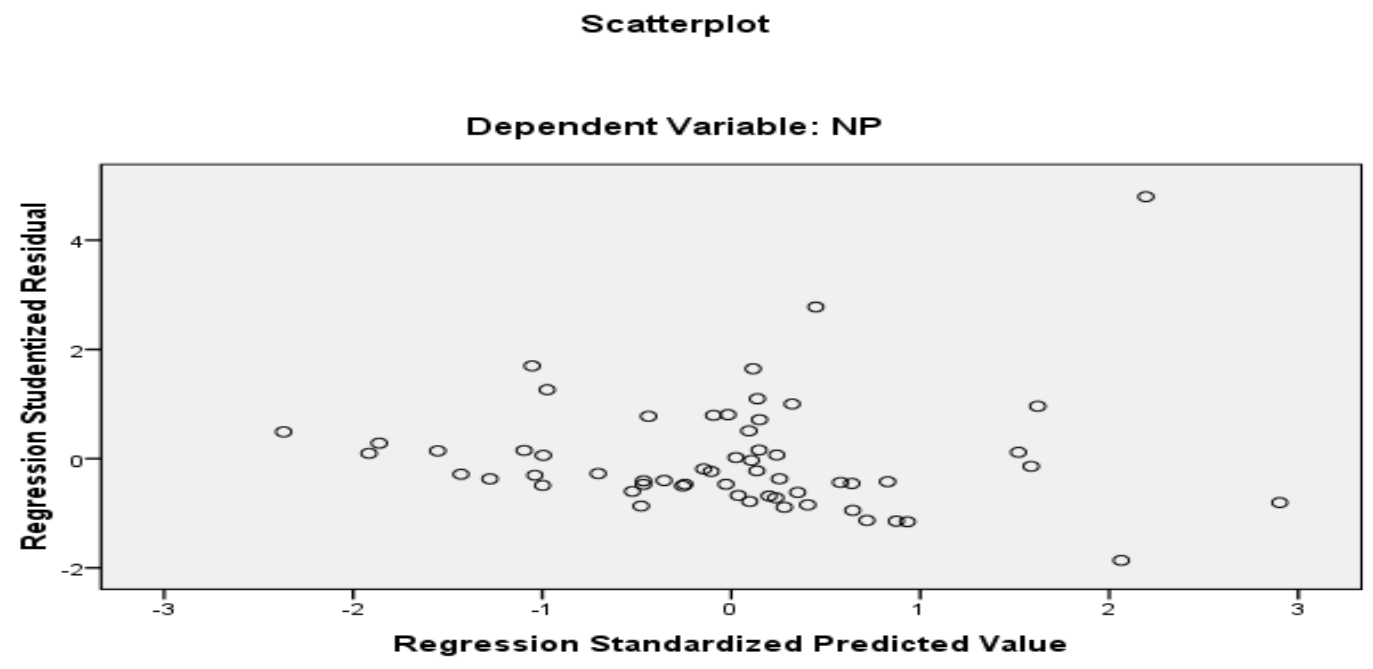

Gambar 2. Uji Normalitas

Sumber: Diolah Peneliti (2020)

Hasil pengujian autokorelasi melalui DW, dihasilkan nilai 1,814 berada pada $1,55-2,46$. Data bebas dari gejala autokorelasi.

\section{Hasil Multipel Regresi Analisis}

Tabel 1. Hasil Multiple Regression Analysis

\begin{tabular}{|l|c|c|c|c|}
\hline \multicolumn{1}{|c|}{ Variable } & Coeffocient & $\mathrm{T}$ & Sig & Simpulan \\
\hline Likuiditas (CR) & $-.0,517$ & $-2,291$ & 0.026 & Berpengaruh \\
\hline $\begin{array}{l}\text { Growth Opportunity } \\
(\mathrm{GO})\end{array}$ & $-.0,567$ & $-2,615$ & 0.012 & Berpengaruh \\
\hline
\end{tabular}


Ati Retnasari, Supami Wahyu Setiyowati, Mochamad Fariz Irianto : Profitabiltas Memoderasi Likuiditas Dan Growth Opportunity Terhadap Nilai Perusahaan

\begin{tabular}{|l|l|l|l|l|}
\hline CR*ROA & $0, .840$ & 2,328 & 0.024 & Terjadi moderasi \\
\hline GO*ROA & 0.501 & 2,041 & 0.046 & Terjadi moderasi \\
\hline
\end{tabular}

Sumber: Diolah Peneliti (2020)

\section{HASIL DAN PEMBAHASAN}

\section{Hubungan Likuiditas terhadap nilai perusahaan}

Mampunya perusahaan pembayaran current liabililities atau hutang jatuh tempo. Kewajiban perusahaan jangka pendek terhadap pihak lain memiliki pengaruh menurunkan nilai perusahaan. Perusahaan harus bias memastikan current liabililities atau jatuh tempo bias dibayar tepat waktu agar kredibilitas perusahaan. Untuk memperkecil risiko likuiditas seharusnya emiten lebih memperkuat nilai likuiditas (Irham, 2011)

Hasil penelitian (Fajaria \& Isnalita, 2018) menyatakan llikuiditas berpengaruh negatif signifikan terhadap nilai perusahaan. (Rompas, 2013) menyatakan bahwa likuiditas mempunyai pengaruh negatif dan tidak signifikan pada nilai perusahaan. Penelitian ini tidak sejalan dengan (Massie, Areros, \& Rumawas, 2018) menyatakan likuiditas mempunyai pengaruh positif dengan nilai perusahaan.

\section{Growth opportunity berpengaruh terhadap nilai perusahaan}

Tumbuhnya aset ditunjukkan oleh besarnya dana yang teralokasikan oleh emiten dan aktiva. Pertumbuhan aset pada emiten dituntut harus tersedianya dana memadai. Peningkatan pertumbuhan aset memberikan peringatan emiten mampu menggunakan aktivanya dengan optimal. Dengan penjelasan tersebut, maka pemodal sangat memiliki keinginan untuk berinvestasi. Dengan penjelasan lebih yaitu permintaan saham emiten naik dan nilai perusahaan juga naik (Lestari \& Hermanto, 2015).

Growth opportunity berpengaruh negatif terhadap nilai perusahaan. Perusahaan manufaktur di Indonesia pada periode 2015 - 2016 memiliki total asset lebih besar dibandingkan total aset sebelum periode penelitian. Perubahan aktiva pada penelitian dipengaruhi nilai perusahaan. Penelitian ini mendukung (Suwardika \& Mustanda, 2017) menyatakan pertumbuhan mempunyai pengaruh negatif akan tetapi sig pada nilai perusahaan. Peningkatan pertumbuhan akan menurunkan nilai perushaan. (Abdullah et al., 2017) menunjukan tingkat (growth) memengaruhi negatif akan tetapi tidak signifikan pada nilai perusahaan. Penelitian ini bertolak belakang dengan penelitian (Fajaria \& Isnalita, 2018) dinyatakan dengan pertumbuhan memiliki pengaruh positif signifikansi pada nilai emiten.

\section{Profitabilitas memoderasi likuiditas pada nilai perusahaan}

ROA yakni tolak ukur mampunya perusahaan untuk menghasilkan keuntungan seerta aset yang dimiliki oleh emiten. Dengan ini membuktikan bahwa perusahaan yang maksimal menggunakan asetnya untuk menghasilkan laba akan mengurangi penggunaan hutang dalam aktivitas perusahaan. Laba yang tinggi akan meningkatkan nilai perusahaaan (Sutama \& Lisa, 2018). 
Ati Retnasari, Supami Wahyu Setiyowati, Mochamad Fariz Irianto : Profitabiltas Memoderasi Likuiditas Dan Growth Opportunity Terhadap Nilai Perusahaan

Profitabilitas mempekuat hubungan likuiditas terhadap nilai perusahaan. Emiten dengan keefektifan dan keefisienan penggunaan aktiva lancar yang dimiliki terkait pembayaran utang lancarnya, maka memiliki dampak dengan berkurangnya biaya dan laba dapat mengalami peningkatan. Baiknya emiten memperhatikan aset emiten agar bertumbuhnya aset yang meningkat ini menandakan sinyal positif emiten mampu menggunakan asetnya secara optimal. Penyebabnya ialah pemodal akan lebih ingin berinvestasi.

\section{Profitabilitas memoderasi growth opportunity terhadap nilai perusahaan}

ROA menunjukan kemampuan manajemen dalam pengelolaan aset yang tergunakan pada operasi emiten pada penghasilan laba. Laba yang meningkat akan mempunyai dampak pada pertubuhan dan nilai emiten. Hal ini memiliki arti sinyal positif bagi investor serta calon investor untuk penanaman modalnya diperusahaan.

Profitabilitas memperkuat hubungan growth opportunity terhadap nilai perusahaan semakin emiten tersebut bertumbuh maka kemampuan emiten untuk menghasilkan laba semakin tinggi, dengan arti harus tetap membuat prospek baik, serta memicu pemodal lebih peningkatan permintaan saham. Peningkatan permintaan saham memberikan nilai perusahaan serta memacu pemodal meningkatkan permintaan saham.

\section{KESIMPULAN}

Hasil pengujian yang dilakukan pada penelitian ini menunjukkan beberapa hal. Likuiditas memberikian pengaruh negatif pada nilai perusahaan. utang lancar lancar lebih tinggi dari pada aset lancar. Hal ini yang menyebabkan likuiditas memengaruhi negatif pada nilai perusahaan. Pertumbuhan perusahaan memengaruhi negatif pada nilai emiten. Hal ini di sebabkan aset pada saat periode penelitiaan lebih besar dari pada periode sebelumnya. Profitabilitas memperkuat keterkaitan likuiditas dengan nilai perusahaan. Rasio ROA menghasilkan laba dengan mamaksimalkan aset mampu mengurangi hutang lancar yang berdampak meningkatkan nilai perusahaan. Profitabilitas memperkuat pertumbuhan terhadap nilai perusahaan.Rasio yang menghasilkan laba perusahan dengan memaksimalkan aset berdampak pada peningkatan pertumbuhan dan meningkatkan nilai perusahaan.

Saran yang diberikan bagi penelitian selanjutnya yaitu, bagi emiten untuk diperhatikan likuiditasnya supaya tidak terlalu tinggi karena hasil penelitian ditunjukkan pengaruh negatif likuiditas terhadap nilai perusahaan, pengelolaan aset lancar dan hutang lancar diperlukan perhatian terkait ditentukannya tingkat yang lebih optimal. Terkait dengan variabel pertumbuhan perusahaan, baiknya emiten memperhatikan aset emiten agar bertumbuhnya aset yang meningkat ini menandakan sinyal positif emiten dalam penggunaan aktiva dengan optimal. Penyebabnya ialah pemodal akan memiliki keinginan melakukan investasi, dengan artian permintaan saham emiten meningkat dan akhirnya nilai emiten 
Ati Retnasari, Supami Wahyu Setiyowati, Mochamad Fariz Irianto : Profitabiltas Memoderasi Likuiditas Dan Growth Opportunity Terhadap Nilai Perusahaan

juga meningkat. Terkait dengan profitabilitas perusahaan harus tetap membuat prospek baik, dengan artian memicu pemodal lebih ditingkatkannya permintaan saham. Permintaan saham mengalami peningkatan akan memberikan nilai positif emiten dan memacu pemodal meningkatkan permintaan saham. Terkait peneliti berikutnya perlu menambah beberapa variabel yang diindikasikan dapat mempengaruhi nilai perusahaan dengan contoh Cash Flow, kesempatan investasi, kebijakan dividen dan lain sebagainya.

\section{DAFTAR PUSTAKA}

Abdullah, N. A. I. N., Ali, M. M., \& Haron, N. H. (2017). Ownership Structure, Firm Value and Growth Opportunities: Malaysian Evidence. Advanced Science Letters, 23(8), 7378-7382.

Fajaria, A. Z., \& Isnalita, N. (2018). The Effect of Profitability, Liquidity, Leverage and Firm Growth of Firm Value with its Dividend Policy as a Moderating Variable. International Journal of Managerial Studies and Research (IJMSR), 6(10), 55-69.

Irham, F. (2011). Analisa Laporan Keuangan, cetakan pertama. Penerbit: Alfabeta, Bandung.

Jacob, J., \& Taslim, F. A. (2017). The impacts of the ratio of liquidity, activity and profitability towards company value with dividend policy as intervening variables. IOSR Journal of Business and Management (IOSR-JBM). ISSN, 23197668 .

Kasmir. (2018). Analisis Laporan Keuangan. Jakarta: PT.Raja Grafindo Persada.

Lestari, S. D., \& Hermanto, S. B. (2015). Pengaruh Capital, Asset, Earning Dan Liquidity Terhadap Perubahan Harga Saham Bank. Jurnal Ilmu Dan Riset Akuntansi, 4(9), 1-22.

Massie, R. N., Areros, W. A., \& Rumawas, W. (2018). Pengaruh Stres Kerja Terhadap Kinerja Karyawan Pada Kantor Pengelola IT Center Manado. JURNAL ADMINISTRASI BISNIS (JAB), 6(002).

Oh, S., \& Kim, W. S. (2016). Effects of ownerships changes and growth on firms values at the issuances of bonds with detacthable warants. Journal of Business Economics and Management, 17(6), 901-915.

Rompas, G. P. (2013). Likuiditas Solvabilitas Serta Rentabilitas Pada Nilai Perusahaan Bumn Yang Terdaftar Di BEI. Jurnal EMBA: Jurnal Riset Ekonomi, 
Ati Retnasari, Supami Wahyu Setiyowati, Mochamad Fariz Irianto : Profitabiltas Memoderasi Likuiditas Dan Growth Opportunity Terhadap Nilai Perusahaan

Manajemen, Bisnis Dan Akuntansi, 1(3).

Sari, H. K., \& Priyadi, M. P. (2016). Faktor-faktor yang memengaruhi Audit Delayd pada perusahaan Manufaktur Tahun 2010-2014. Jurnal Ilmu Dan Riset Akuntansi (JIRA), 5(6).

Sari, P. I. P., \& Abundanti, N. (2014). Pengaruh tumbuhnya emiten serta leverage terhadap profitabilitas dan nilai perusahaan. E-Jurnal Manajemen Universitas Udayana, 3(5).

Suastini, N. M., Purbawangsa, I. B. A., \& Rahyuda, H. (2016). Hubungan kepemilikan manajerial dan pertumbuhan perusahaan terhadap nilai perusahaan pada perusahaan manufaktur di Bursa Efek Indonesia (struktur modal sebagai variabel moderasi). E-Jurnal Ekonomi Dan Bisnis Universitas Udayana, 5(1), 143-172.

Sutama, D., \& Lisa, E. (2018). Pengaruh Leverage Serta Profitabilitas Pada Nilai Perusahaan. JSMA (Jurnal Sains Manajemen Dan Akuntansi), 10(1), 21-39.

Suwardika, I. N. A., \& Mustanda, I. K. (2017). Pengaruh ukuran perusahaan, leverage, pertumbuhan perusahaan, dan profitabilitas terhadap nilai perusahaan pada perusahaan properti. E-Jurnal Manajemen Universitas Udayana, 6(3).

Tahu, G. P., \& Susilo, D. D. B. (2017). Effects of Liquiditys, Leverages and profitability to The Firm Value (Dividend Policy as Moderating Variable) in Manufacturing Company of Indonesia Stock Exchange. Research Journal of Finance and Accounting, 8(18), 1697-2222.

Tandelilin, E. (2010). Portofolio dan Investasi: Teori dan aplikasi. Kanisius.

Weston, J. F., \& Copeland, T. E. (2008). Manajemen keuangan Kesembilan. Penerbit Binarupa Aksara. Jakarta. 